\title{
SAZONALIDADE DE COLEOPTEROFAUNA EM FRAGMENTO FLORESTAL DE NOVA FRIBURGO, RJ.
}

\section{Thais Berçot Pontes Teodoro' \\ Magali Hoffmann²}

Resumo: Coleoptera é a mais diversa dentre as ordens da classe Insecta. Com o objetivo de conhecer mais acerca da fauna local, foi realizado um levantamento da ordem em um fragmento de mata localizada no centro do Município de Nova Friburgo, RJ. Foram utilizadas armadilhas tipo "pitfall", distribuídas em três pontos da mata: borda próxima ao lago, interior e borda afastada do lago. Os parâmetros analisados foram sazonalidade, riqueza e abundância de indivíduos. Os resultados obtidos revelaram uma abundância de 25 familias, das quais Staphylinidae, Hydrophilidae, Nitidulidae e Scarabaeidae se caracterizaram como dominantes. A abundancia e riqueza da coleopterofauna foi maior nos períodos mais quentes e úmidos do ano, como observado em outros trabalhos.

Palavras-chave: Levantamento; Insecta; Mata Atlântica; Pitfall.

\footnotetext{
${ }^{1}$ Ciências Biológicas/ Universidade Estadual Norte Fluminense, Brasil. E-mail:thaisbercot@yahoo.com.br.

2 Ciências Biológicas/ Universidade Estadual Norte Fluminense, Brasil. E-mail: magali@uenf.br.
} 